---مجلة علوم الرافدين، المجلد 27، العدد 4 /عدد خاص بالمؤتمر العلمي الثالث لعلوم الحياة، ص 162-168، 2018----

أول تشخيص للفطر Fusarium poae المسبب لتعفن جذور الحنطة في شمال العراق

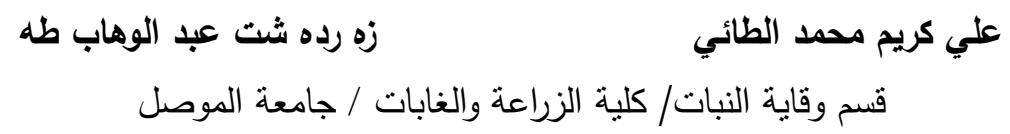

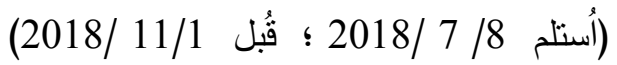

أظهرت نتائج المسح الحقلي الذي أُجري في حقول محافظتي نينوى و أربيل بهدف معرفة مدى انتشار مرض تعفن جذور

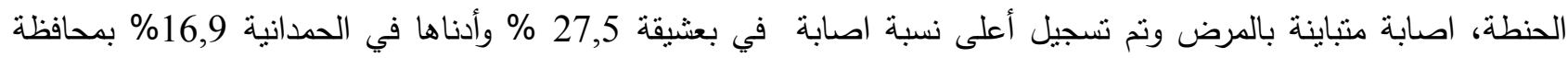

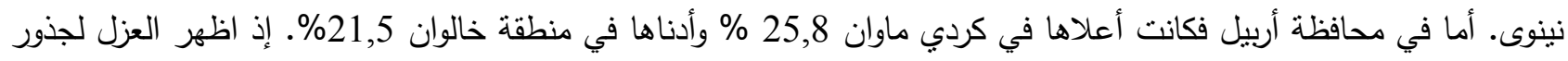
Bipolaris sorokiniana (Sacc.) و Fusarium poae (Peck) نباتات الحنطة المصابة بالتعفن عن ظهور الفطريات . Wollenw. F.culmorum (Wm.G. Smith) Sacc. g F. graminearium (Schwabe ) ghomaker تسجيل الفطر F.poae الأول من نوعه على الحنطة في العراق ونم ناكيد التشخيص للفطريات المعزولة بالتشخيص الجزيئي وباستخدام تقنية تفاعل البلمرة المنسلسل، PC ) Polymerase Chain Reaction وتعد هذه اول دراسة لتتخيص الفطر بتقنية البلمرة المتسلسل في العراق، إذ أظهرت جميع الفطريات القدرة على اصابة الحنطة بمرض تعفن الجذور.

الكلمات الدالة: فطر Fusarium poae، تعفن جذور الحنطة، PCR.

\title{
First Record of Fusarium poae, Wheat Root Rot Fungus in the North of Iraq
}

\author{
Ali K. AL-Taee \\ Zardasht A. Taha \\ Department of Plant Protection/College of Agriculture and Forestry/ University of Mosul
}

\section{ABSTRACT}

The Results of field survey conducted in Ninevah and Erbil governorates to assess the distribution of root rot disease in wheat have shown variability in infection levels. In Ninevah; the highest infestation of \%27.5 was reported from Bashika, and lowest of \%16.9 from Hamdaniyeh, and in Erbil;the highest infestation of \%25.8 was reported in Grdy Mawan and lowest of \%21.5 was in Khalwan. Isolates from root rot infected wheat plants shown the appearance of Bipolaris sorokiniana (Sacc.) Shomaker, Fusarium graminearium (Schwabe), F. culmorum (Wm. G. Smith) Sacc and and F.poae (Schwabe) as first found and recorded on wheat in Iraq, the fungus $B$. sorokiniana recorded the highest isolation rate of \%54.1 in Tallafar and lowest rate of \%37.1 in Qapakian, followed by F.culmorum which recorded a range of isolation between $\% 22.1$ and \%25.4. Identification of isolated fungi were confirmed by conducting Polymerase Chain Reaction (PCR) molecular test using 2 specific primers FP82F and FP82R. The expected PCR product (220 bp) obtained from a specific molecular marker (FP82), confirmed that they belong to fungus $F$. Poae. However, this is the first molecular study indicates clearly the presence of $F$. Poae in Iraq.

Keywords: Fusarium poae, wheat root rot, PCR. 


\section{المقدمة}

تنتمي الحنطة . Triticum aestivum الى العائلة النجيلية Poaceae وهي من أقدم الدحاصيل الزراعية التي عرفها الانسان إذ نزرع على نطاق واسع وتتتج بكميات كبيرة، وترجع كثير من الخسائر الاقتصادية في المحاصيل الزراعية إلى إصابتها

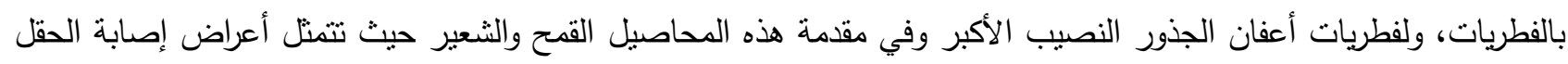

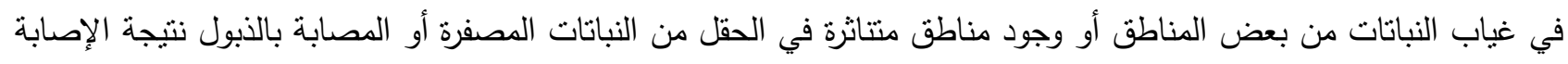

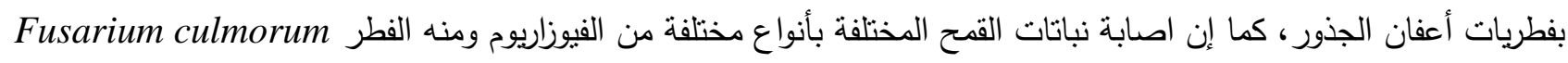
يُعد السبب الرئيس في نأثر محصول القمح في شمال غرب المحيط الهادي، وقد ارتبطت شدة المرض عكسياً بارتفاع النباتات وذللك لثلاثة أنواع من الفيوزاريوم، كما ساهمت بشكل واضح في خفض فئر عدد السنابل وإصابتها بالعفن، وكان أنثدها ضرراً على ونى , 2005 ; Smily and Patterson, 1996)

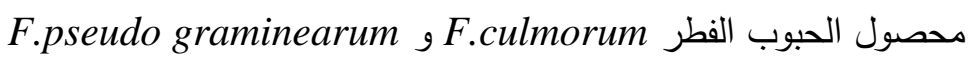

.(Smiley

وفي العراق أجريت دراسات على تعفن جذور الحنطة في المناطق الأروائية و اتضح انتشار الفطريات Bipolaris Rhizctonia solani و Macrophominia phaseoliana, C.globosum, Chaetomium elatum و sorokiniana

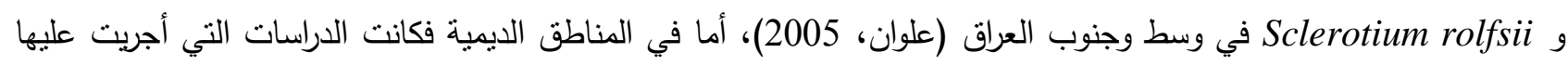
محدودة واقتصرت على تسجيل الفطر Fusarium culmorum بوصفة مسبباً لتعفن الجذور (محمد، 1978). كما ذكر الراشدي

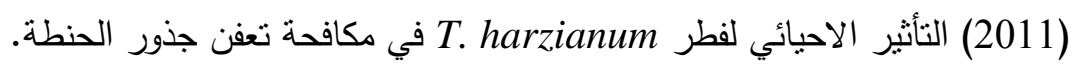
ونظراً لانتشار المرض في حقول زراعة الحنطة وتزايدها في السنوات الأخيرة في مناطق عديدة ولاستيما في العراق ارتأينا

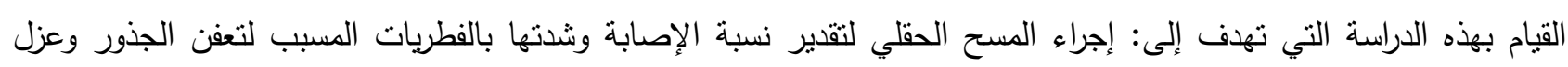
وتشخيص واختبار القدرة الإمراضية لعزلات الفطر المسبب لتعفن الجذور وإجراء تشخيص الفطريات باستخدام تفاعل البلمرة

\section{المواد وطرائق العمل}

المستح الحقلي: أجري المسح الحقلي للتحري عن وجود مرض تعفن جذور الحنطة في شهري نيسان وأيار في سنة 2012 في

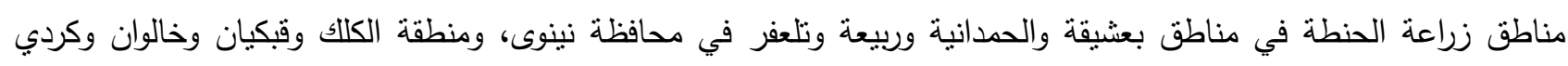

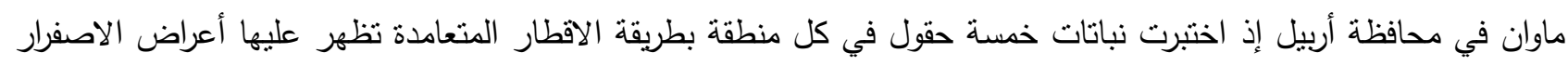

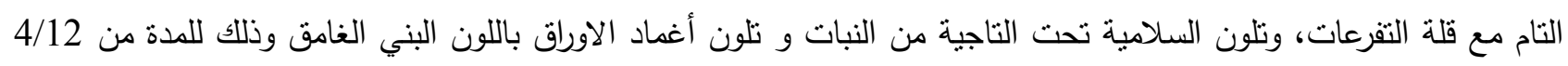
إلى 2012/5/10 وتم حساب النسبة المئوية للإصابة حسب المعادلة الآتية.

عدد النباتات المصابة

$100 x$ = الإصابة

العدد الكلي للنباتات المأخوذة

العزل و التثخيص: أخذت عينات من نباتات الحنطة المصابة المأخوذة من منطقة السلامية تحت التاجية والجذر المصاب لنباتات الحنطة وغسلت بالماء الجاري لمدة نصف ساعة لإزالة الأتربة العالقة بها، ثم قطعت بواسطة مشرط معقم إلى أجزاء

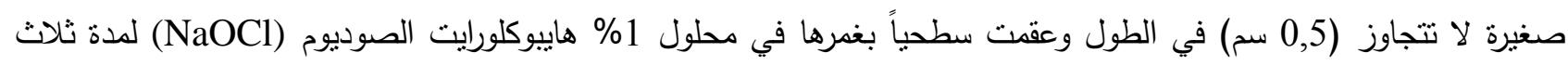
دقائق، وجفقت القطع بين ورقتي ترشيح ثم زرعت في أطباق بتري معقمة تحتوي على وسط أكار البطاطا والدكستروز 
(PDA) Dextrose Agar

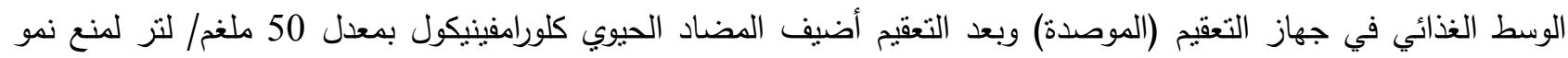

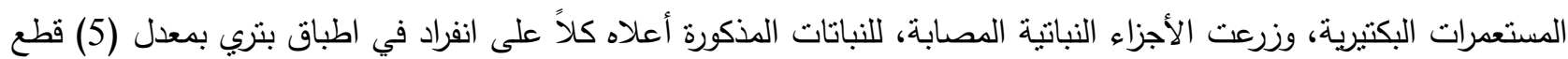
اطبق وحضنت الأطباق في الحاضنة في درجة حرارة (25×25) سيليزية لمدة خمسة الى سبعة أيام.

شخصت الفطريات النامية إلى مستوى الجنس حسب مفاتيح Harnnet و Hunter التصنيفية (2006) لمرنبة النوع بالاعتماد على (2002) (2006) ; Kumar et al., (2002) ; Chand et al., (20) وقد تم تتمية Fusarium عusarium الخاص بتشخيص انواع الفيوزاريوم Carnation leaf Agar (CLA) على أوراق القرنفل

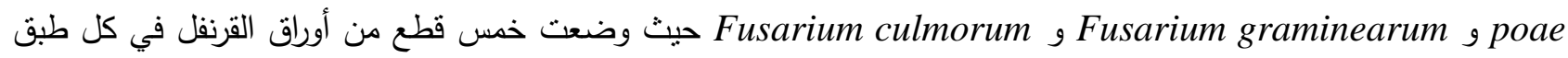
بعد تعقيمه. وحسبت النسبة المئوية لعدد الفطريات المعزولة من النباتات المصابة لكل منطقة من خلال المعادلة الآتية. عدد مرات ظهور النوع الواحد

$100 x$

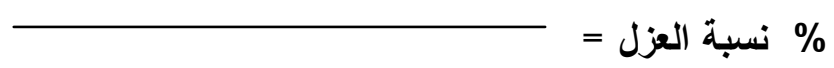

العدد الكلي للفطريات المأخوذة

استخلاص الحامض النووي DNADن الفطريات المنماة في البيئة الغذائية:

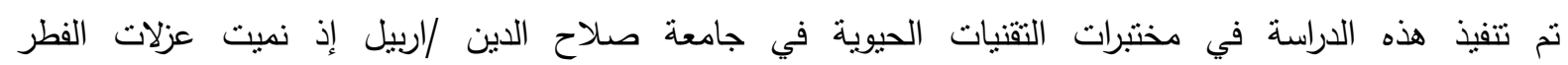
F.poae و F.graminearum و F.culmorum B.sorokiniana حرارة 25+2 سن لمدة سبعة أيام.

\section{استخلاص الحامض DNA من الفطر المنمى على الوسط :}

تم استخدام خمس عزلات من الفطر . Fusarium spp وعزلة واحدة من B.sorokiniana التي سبق عزلها من جذور وتاج نباتات الحنطة المصابة لمناطق مختلفة في محافظتي نينوى واربيل ثم نميت هذه العزلات في بيئة PDA في دن درنة

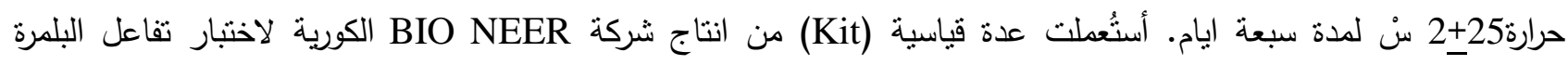
المتسلسل، لغرض استخلاص الحامض النووي، واتبع البروتوكول الخاص بالثركة المجزة للعدة القياسية في استخلاص الـ .DNA

تثخيص عزلة الفطر Fusarium poae باستخدام بوادئ متخصصة:

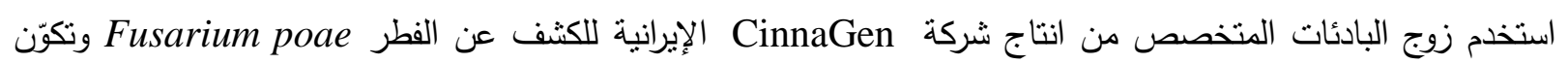
البادئان من التتابعات الآتية:

Fusarium poae الجدول1: التتابعات لزوج البادئات المتخصصة للكثف عن الفطر

\begin{tabular}{|c|c|c|c|}
\hline 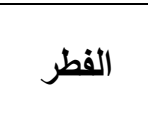 & 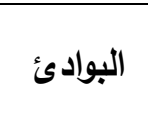 & التتابع 5-3 & $\begin{array}{c}\text { حجم أزواج القواعد } \\
\text { (bp) }\end{array}$ \\
\hline \multirow[b]{2}{*}{ F. poae } & Fp-82F & CAA GCA AAC AGG CTC TTC ACC & \multirow[t]{2}{*}{220} \\
\hline & Fp-82R & TGT TCC ACC TCA GTG ACA GGT & \\
\hline
\end{tabular}




$$
\text { علي كريم محمد الطائي و زه رده شت عبد الوهاب طه }
$$

Master من إنتاج شركة BIO NEER ماستخدم Master mix لاختبار تفاعل السلسلة المتبلمر حيث تحتوي كل أنبوبة

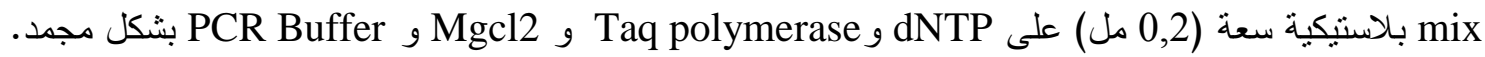
ثم أضيف ماء مقطر معقم للبوادىء لكل منها بحسب التوصيات المعمول بها لكل بادئ من قبل الثركة المنتجة وذلك

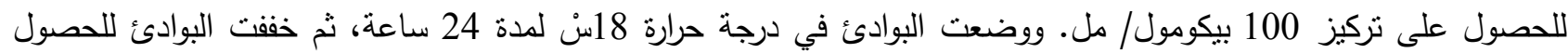

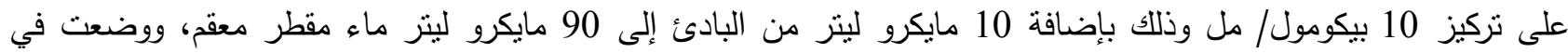
أنابيب بلاستيكية جديدة (Epindorff tube) وحفظت في المجمدة لحين الاستخدام. وحُضِّر خليط التفاعل بإضـافة 1,25 مايكرو ليتر من كل شريط من شريطي البادئ و 4 مايكرو ليتر من الدنا للفطر

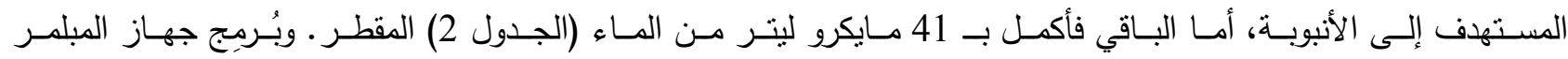

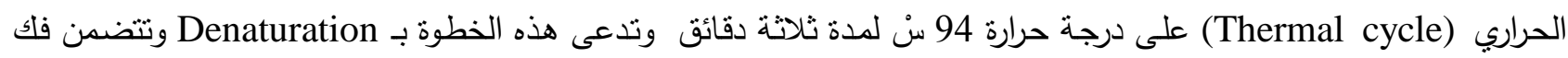
شريط الدنا المزدوج لأجل الحصول على شريط مفرد من الدنا، حيث سيعمل هذا الثريط فيما بعد كقالب للتفاعلات اللاحقة وبذللك يزداد عدد القطع في كل دورة بشكل متتالية هندسية. وضبط الجهاز على 30 دورة يتم خلالها مضاعفة قطع الدنا وتضمنت : الجدول 2: ضبط جهاز PCR عند استخدام البوادئ المتخصصة

\begin{tabular}{|c|c|c|c|c|c|c|}
\hline Primer & $\begin{array}{c}\text { Initial } \\
\text { Denaturatio }\end{array}$ & $\begin{array}{c}\text { Denaturation } \\
\text { temperature }\end{array}$ & $\begin{array}{c}\text { Annealing } \\
\text { temperature }\end{array}$ & $\begin{array}{c}\text { Extension } \\
\text { temperature }\end{array}$ & $\begin{array}{c}\text { Final } \\
\text { Extension } \\
\text { temperature }\end{array}$ & $\begin{array}{c}\text { Hold } \\
\text { temperature }\end{array}$ \\
\hline $\begin{array}{l}\text { Fp82F } \\
\text { Fp82R }\end{array}$ & 94 سن، 90 ثانية. & 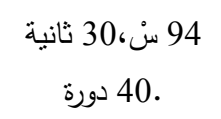 & . 62 سن،30 دورة ثانية & 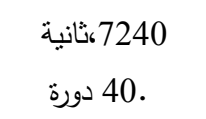 & 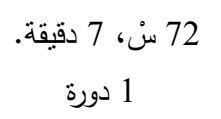 & 4 سن \\
\hline
\end{tabular}

\section{النتائج والمناقشة}

المسح الحقلي: أظهرت نتائج المسح الحقلي الذي أُجري في حقول محافظتي نينوى وأربيل لمعرفة مدى انتشار مرض تعفن جذور الحنطة، ظهور نسب إصابة متباينة بالمرض في محافظة نينوى في كل من بعشيقة وتلعفر والحمدانية وربيعة خلال شهر نيسان

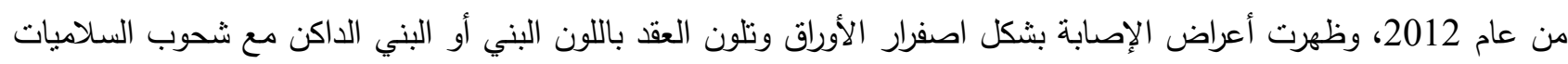

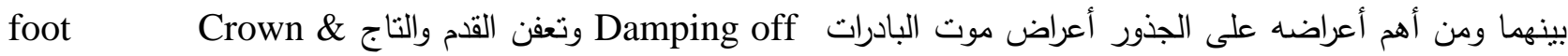
root rot

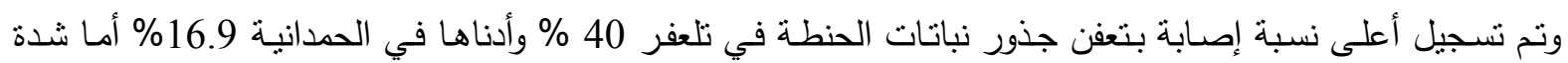
الإصابة فكانت أعلاها في منطقة تلعفر 0,4 وادناها في منطقة ربيعة 0.25. أما في محافظة أربيل فكانت اعلى نسبة للإصـابة

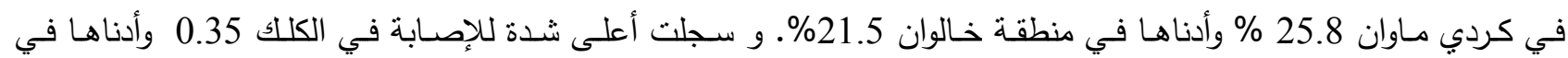

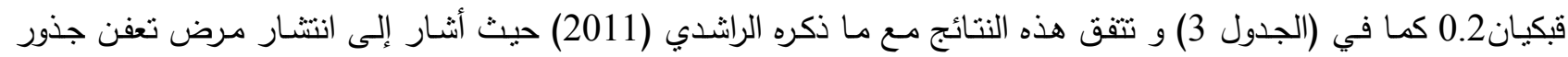
الحنطة في محافظة نينوى بنسبة وصلت إلى 34,32 \% وما ذكره الكبيسي (2013) عن انتشار مرض تعفن الجذور في المناطق الديمية من العراق ومهع خليفة (2013) من خلال المستح الحقلي الذي أجري في حقول الحنطة في جميع مناطق زراعة الحنطة التي شملها المسح.

الجدول 3: إصابة نباتات الحنطة بمرض تعفن جذور في محافظتي نينوى واربيل خلال شهري نيسان وايار 2012

\begin{tabular}{|c|c|c|c|c|c|c|c|c|}
\hline \multicolumn{4}{|c|}{ محافظة أربيل } & \multicolumn{4}{|c|}{ محافظة نينوى } & \multirow[t]{2}{*}{ المعاملات } \\
\hline كردي ماوان & خالوان & قبكيان & الكلك & ربيعة & الحمدانية & بمثيقة & تلعفر & \\
\hline
\end{tabular}




\begin{tabular}{|l|l|l|l|l|l|l|r|r|}
\hline 25.8 & 21.5 & 24.5 & 25.5 & 22.5 & 16.9 & 27.5 & 40 & 0.4 \\
\hline 0.22 & 0.25 & 0.20 & 0.35 & 0.25 & 0.35 & 0.32 & 0.4 & شلإصة الإصابة \\
\hline
\end{tabular}

العزل والتشخيص المجهري: تم ظهور مستعمرات هوائية شاحبة اللون بنية محمرة الأبواغ الكونبدية كبيرة نسبياً فضلا عن قصرها وتحتوي على ثلاثة حواجز في الغالب وأحياناً أربعة الحواجز وكانت معقوفة و منحنية (مقوسة ومستدقة) مع وجود الخلية القمية

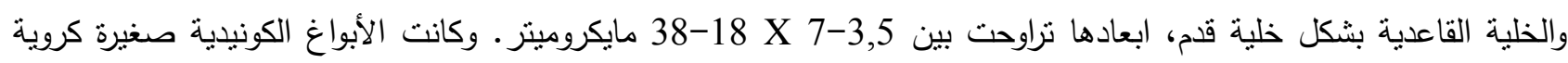
مهمازية الثكل وتحتوي على حلمة و تتكون من خلية واحدة واحيانا تحتوي على حاجز واحد و أبعادها 5-8 X 5 X 5 مايكرومينز

كذلك كانت الأبواغ الكلاميدية غزيرة متجمعة أو بشكل سلاسل في المايسيليوم القديم. وتتقق هذه المواصفات مع الفطر (Fp) ) Leslie and Summerell, الذي تطابقت مواصفاته مع ما ذكره Fusarium poae (2006) (Peck) Wollenweber .Stenglein (2009) ; Nelson et al., (1983 B. sorokiniana الممرض الأول من نوعه على الحنطة في العراق. ولقد سبق نسجيل الفطريات F.poae و F.culmorum و Framinearum على الحنطة عند الراشدي (2011) في محافظة نينوى وفي المناطق الإروائية عند علوان (2005) و خليفة (2013). ويبين (الجدول 4) اختلاف نسب عزل الفطريات في مناطق محافظتي نينوى واربيل ويُلحظ الذئ

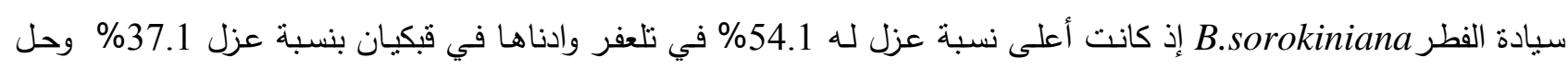
الفطر F.culmorum ثانيا وبنسبة عزل انحصرت بين 20.2 -25.4\% وبلغت نسبة عزل الفطر عند 20.7 \% في قبكيان وادناها عند 10.4\% في الحمدانية اما الفطر F.poae فبلغت نسبة عزله بين 10.4- 19.1 \% \% وتعد الفطريات الثلاثة F.graminearum و F.culmorum و من المسبيات المرضية البارزة لتعفن جذور

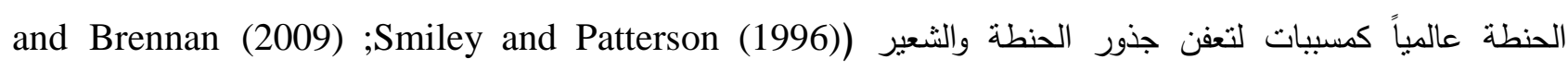
Murray

الجدول 4: الفطريات المعزولة من عينات الحنطة المصابة بمرض تعفن الجذور من مناطق محافظتي نينوى واربيل

\begin{tabular}{|c|c|c|c|c|c|c|c|c|}
\hline \multicolumn{8}{|c|}{ 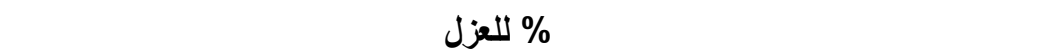 } & \multirow{3}{*}{ الفطريات } \\
\hline \multicolumn{4}{|c|}{ محافظة أربيل } & \multicolumn{4}{|c|}{ محافظة نينوى } & \\
\hline كردي ماوان & خالوان & قبكيان & الكلك & ربيعة & الحمدانية & بعشيقة & تلعفر & \\
\hline 2.2 & 3.0 & 4.5 & 6.0 & 5.0 & 7.2 & 6.5 & 4.3 & Alternaria sp \\
\hline 40.0 & 38.5 & 37.1 & 44.1 & 39.5 & 47.1 & 39.1 & 54.1 & B. B.sorokinana \\
\hline 22.2 & 25.4 & 20.2 & 21.1 & 24.4 & 22.2 & 21.2 & 21.1 & F. $\quad$ F.culmorum \\
\hline 17.5 & 14.5 & 20.7 & 13.4 & 14 & 12.5 & 20.1 & 10.4 & F. $\quad$ F.graminearum \\
\hline 17.2 & 19.1 & 17.5 & 15.4 & 17.1 & 11.13 & 13.1 & 10.4 & F. F.poae \\
\hline
\end{tabular}

التشخيص الجزيئي للفطر F.poae المعزول من الحنطة:

أظهرت نتائج التشخيص الجزيئي للفطر باستعمال تقنية تفاعل البلمرة المتسلسل، Polymerase Chain Reaction وذللك باستخدام زوج البادئات المتخصصة FP82F و FP82R)

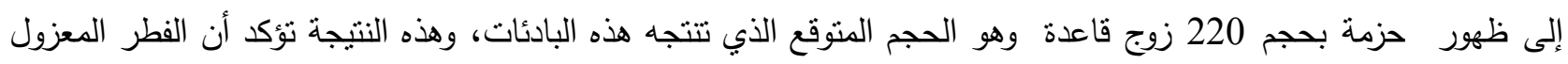




$$
\text { علي كريم محمد الطائي و زه رده شت عبد الوهاب طه }
$$

هو F.poae وتعد هذه اول دراسة في بابها لنتخيص الفطر بتقنية البلمرة المتسلسل في العراق وهذا يؤكد التشخيص السابق. كما

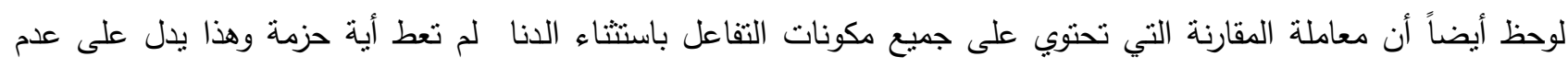

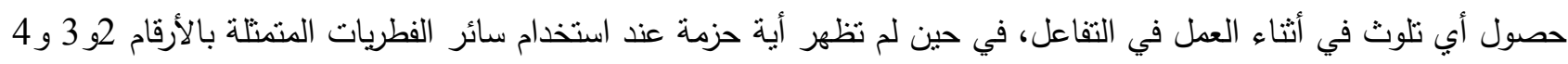

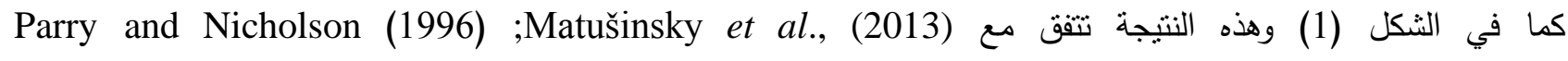
الذين أثناروا إلى تثخيص عدة عزلات من الفطر Fszczółkowska et al., (2013);

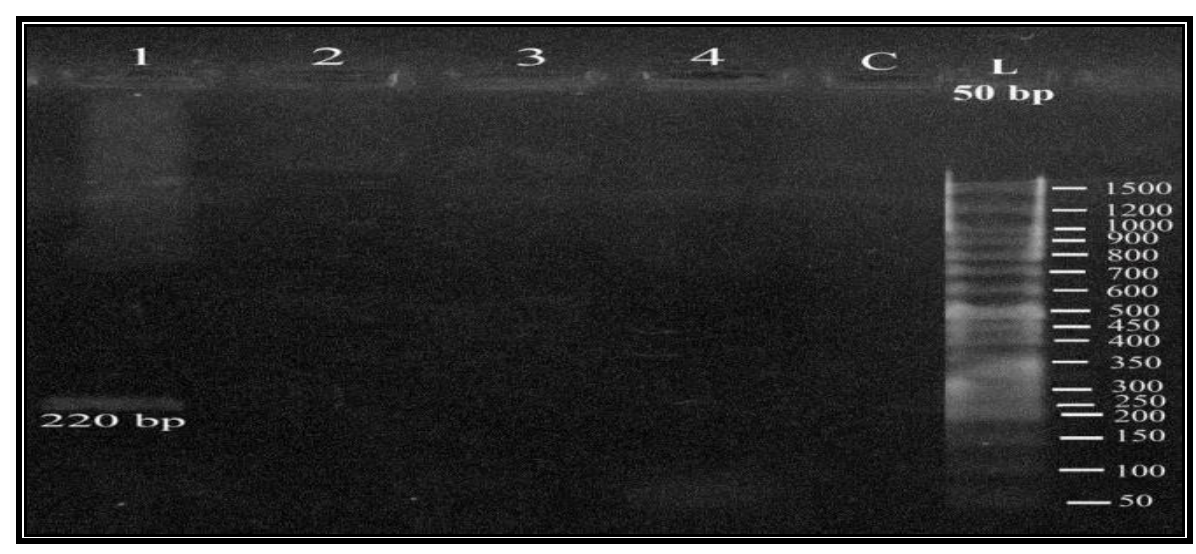

المتسلسل.

الثكل 1: الترحيل الكهريائي لنواتج تفاعل البلمرة المتسلسل على هلام الاكاروز باستخدام زوج البادئات FP82F و

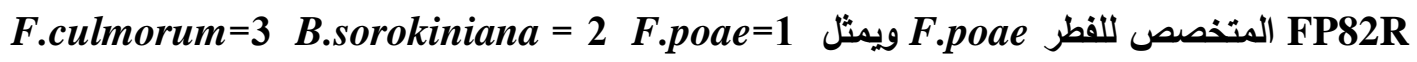
c F.graminearum=4

\section{المصادر العربية}

خليفة، محمد حمود (2013). التشخيص الجزيئي لمسبب مرض تعفن التاج في الحنطة وتقييم بعض طرائق المكافحة. رسالة ماجستير ، كلية الزراعة، جامعة بغداد.

خليفة، محمد؛ الأحمد، أحمد؛ بيرق، محمد موفق؛ نشيط، ميلودي (2006). تباين الخصدائص المزرعية

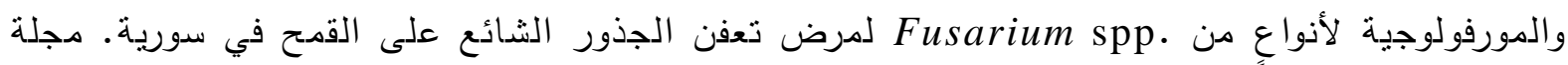

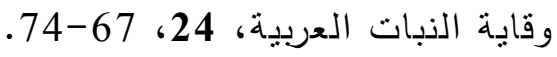

الراثندي، وسن علي سعود (2011). المكافحة الحيوية لتعفنات الجذور وتفحم الحنطة في الترب غير المحروثة. رسالة ماجستير، كلية الزراعة والغابات، جامعة الموصل.

علوان، صباح لطيف (2005). إمكانية تصنيع مبيد احيائي من الفطر Trichoderma harzianum Rifai لمكافحة مرض ولف تعفن البذور وموت بادرات في الحنطة. أطروحة دكنوراه، كلية التربية للبنات، جامعة الكوفة . الكبيسي، علي صادق محمد (2013). تشخيص الفطريات المرافقة لمرض تعفن جذور الثعبر في محافظة نينوى وإمكانية

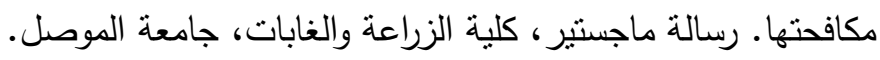
محمد، عبدالعزيز (1978). دراسات على مرض الحبوب المنسبب عن الفطر فيوزاريوم كلمورم. زراعة الرافدين. 13. دليل قسم وقاية النبات. كلية الزراعة والغابات. جامعة الموصل. 94 صرسير. 


\section{المصادر الأجنبية}

Barnett, H.L.; Hunter, B.B. (2006). "Illustrated Genera of Imperfect Fungi". APS Press, 218 pp.

Chand, R.; Singh, H.V.; Joshi, A.K.; Duveiller, E. (2002). Physi-ological and morphological aspects of Bipolaris sorokiniana conidia surviving on wheat straw. Plant Pathol. J., 18, 328-332.

Kumar, J.P.; Schafer, R.; Huckelhoven, G.; Langen; Baltruschat, H.; Stein, E.; Subramanian, N.; Kogel, K.H.; Kumar, J.; Nagarajan, S. (2002). Bipolaris sorokiniana, acereal pathogen of global concern: cytological and molecular approaches towards better control. Mol. Plant Pathol, 33, $338-351$.

Leslie, J.F.; Summerell, B.A. (2006). The Fusarium, Laboratory Manual. Black Well Publishing. $288 \mathrm{p}$.

Matušinsky, P.; Polišenská, I.; Kadlíková., M.; Tvarůžek., L.; Spitzerová, D.; Spitzer, T. (2013). Dynamics of T-2 toxin synthesis on barley ears. J. Food, Agric. Environ, 11(3 and 4), 1114 $-1122$.

Murray, G.M.; Brennan, J.P. (2009). The current and potential costs from diseases of wheat in Australia. Grains Research and development corporation. 208p.

Nelson, P.E.; Toussoun, T.A.; Marasas, W.F.O. (1983). "Fusarium species: An Illustrated Manual for Identification". Pennsylvania State University Press, University Park. Pennsylvania, 122 p.

Parry, D.W.; Nicholson, P. (1996). Development of a PCR assay to detect Fusarium poae in wheat. Plant Pathology 45, 383- 391.

Pszczółkowska, A.; Okorski, A.; Jarmołkowicz, J. (2013). Fungal pathogens of the genus fusarium in winter. 62(2).

Smiley, R.W. (2005). "Compendium of Wheat Diseases and Pests". $3^{\text {rd }}$ ed. The Pennsylvania State University Press, University Park, MN, USA, 37-39 pp.

Smiley, R.W.; Patterson, L.M. (1996). Winter wheat yield and profitability from Dividend and Vitavax seed treatments. J. Prod. Agric., 8, 350-354.

Stenglein, S.A. (2009). Offered Review Fusarium poae: a Pathogen that needs more attention. J. Plant Pathol., 91, 25-36. 